\title{
GANHOS DE PRODUTIVIDADE DA COOPERAÇÃO PARA INOVAR NAS EMPRESAS INDUSTRIAIS BRASILEIRAS
}

\author{
Ronivaldo Steingraber * \\ Flávio de Oliveira Gonçalves ${ }^{\dagger}$
}

\begin{abstract}
Resumo
Este artigo analisa o impacto da cooperação para inovar sobre a produtividade das empresas industriais brasileiras. Tal exercício é considerado em dois momentos na estimativa realizada. Primeiramente, verifica-se o efeito das competências para inovar na empresa, em seguida estas competências são controladas pelo desempenho setorial, onde é introduzida a variável de cooperação. Os resultados encontrados mostram que as empresas mais produtivas são as que apresentam mão de obra inovadora, maior renda e escolaridade dos trabalhadores, são maiores e com maior volume de importação, já as empresas mais produtivas que cooperam no setor apresentam maior volume de exportações, pedidos de patentes registrados e são maiores na participação setorial.
\end{abstract}

Palavras-chave: Cooperação; Cooperação para inovar; Competências para inovar.

\begin{abstract}
This paper examines the impact of innovative cooperation on productivity of Brazilian industrial companies. This exercise carried out in two steps. First, the effect of capabilities in the firm's productivity is checked, then, these capabilities are controlled by sectorial performance, with the introduction of the variable innovative cooperation. The results showed that the most productive firms have innovative labor, higher income and education of the workers, are larger in size, and have higher value of imports; the most productive firms with cooperation at sector have higher value of exports, a greater number of patent applications, and sectorial participation.
\end{abstract}

Keywords: Cooperation; Cooperation for innovation; Capabilities.

JEL classification: D22, D23, O31, O33.

\footnotetext{
* Universidade Federal da Santa Caratina. E-mail: ronivaldo.steingraber@gmail.com

† Universidade Federal do Paraná. E-mail: flaviogonsalves@hotmail.com
} 


\section{Introdução}

O processo de inovação é visto primordialmente pelo lado da concorrência na Economia. Empresas inovam para conquistar uma vantagem competitiva no mercado frente aos demais concorrentes. Evidências mostram a existência de comportamentos cooperativos em diversas fases do processo de inovação, como a formação de alianças estratégicas, cooperação em $\mathrm{P} \& \mathrm{D}$, joint ventures, redes de empresas, entre outras.

A literatura Schumpeteriana identifica a inovação como sistêmica e envolvendo diversos atores, que em muitos momentos cooperam e não competem pelos recursos para inovar. O avanço da Teoria dos Jogos mostrou que os comportamentos cooperativos são dominantes em diversos processos de escolha na Economia. Não diferentemente, o processo de inovação também apresenta essa característica.

Em virtude do avanço na investigação sobre a cooperação na inovação, este artigo analisa o impacto da cooperação para inovar sobre a produtividade das empresas industriais brasileiras. O exercício empírico é precedido de uma análise sobre o estado atual da cooperação no processo de inovação.

Com a investigação empírica, este trabalho busca identificar como a teoria Schumpeteriana se aproxima da realidade das empresas e por meio desse exercício, propor políticas públicas que viabilizem a inovação na indústria brasileira. O modelo empírico é considerado em dois momentos na estimativa realizada. Primeiramente, verifica-se o efeito das competências para inovar na empresa, em seguida estas competências são controladas pelo desempenho setorial, onde é introduzida a variável de cooperação. Essa divisão obedece à metodologia de construção do modelo de regressão multinível de dois estágios (níveis) apresentado em Hox (2002) e nas estimativas de Steingraber (2009). As competências para inovar e gerar ganhos de produtividade formam as variáveis no nível da empresa e são construídas em função de bases estatísticas como a PIA, RAIS, SECEX, já a cooperação para inovar pertence à base PINTEC.

O controle das variáveis do modelo de regressão multinível é feito em dois estágios. O primeiro estágio considera as competências para inovar das empresas industriais brasileiras pertencentes às bases de dados analisadas e que serão apresentadas na seção três. A cooperação é controlada setorialmente no segundo estágio, dessa forma, a variável setorial considerada (cooperação para inovar) não é uma dummy, mas sim uma variável agrupada pela classificação CNAE 1.0 dos setores industriais brasileiros.

Nesse sentido, o modelo estimado identifica a cooperação para inovar das empresas industriais brasileiras por setor (agrupamento no segundo nível) e seu impacto sobre as competências para inovar (primeiro nível). Os dois níveis são estimados simultaneamente em relação à variável dependente: a produtividade total dos fatores das empresas industriais brasileiras no ano de 2005.

A utilização do modelo de regressão multinível é justificada pela necessidade de separação da influência da empresa e da influência do setor sobre a capacidade de inovação da empresa. Não se considera a decisão de inovar na empresa como variável dependente, o que formaria um modelo com variável binária e restringiria o número de observações. Por meio do modelo utilizado o controle setorial é construído endogenamente por meio do setor ao qual a empresa pertence e neste considera-se a cooperação para inovar como variável de controle do comportamento individual da empresa. O modelo multinível 
permite a correção de possíveis vieses de agregação oriundos do fato que a variância encontrada em uma amostra de firmas quaisquer dentro de uma indústria é menor que aquela encontrada em uma amostra de geral de firmas de todas as indústrias.

Em relação à variável dependente analisada, optou-se pelo uso da produtividade total dos fatores (PTF) e não da presença ou não de inovação na empresa. A PTF permite que as competências da empresa sejam amplas, caso contrário, as empresas consideradas seriam restritas à PINTEC e não, como no caso desse modelo, a PIA, RAIS e SECEX que são bases mais amplas e consideram praticamente a população industrial da economia. A relação entre produtividade total dos fatores e progresso tecnológico é ampla e pertence ao foco da teoria Neoclássica. A contribuição deste artigo está mais relacionada à teoria Schumpeteriana da firma, apesar da utilização da variável dependente de viés Neoclássico. A base teórica heterodoxa é utilizada para sustentar a necessidade de cooperação na empresa e o papel das suas competências microeconômicas e da influência setorial sobre os ganhos de produtividade da empresa. Pelo lado da teoria Neoclássica do progresso tecnológico, este artigo contribuiu com a definição de variáveis que explicam a PTF, não permanecendo com a interpretação de que a PTF é autoexplicativa, mas sim, de que ela é uma medida que deve ser explicada, em razão de a mesma se apresentar tautológica na explicação do desempenho tecnológico da firma sozinha.

A estimativa realizada é conduzida de acordo com o modelo de Steingraber (2009) que relacionou a PTF e as competências para inovação da empresa com a aglomeração e a concentração de mercado, inovação (processo, produto e organizacional), cooperação para inovar, apoio do governo para inovar, financiamento público para inovar, presença de capital estrangeiro, acesso ao mercado externo (exportação) e cooperação com universidades e centros de pesquisa como variáveis de controle setorial.

Os resultados mostraram que os setores industriais brasileiros, de maneira geral, apresentam características particulares que explicam as diferenças de produtividade e acentuam o papel das competências para inovar nas empresas e no setor sobre a PTF. A estimativa do modelo com apenas a variável Cooperação para Inovar busca separar os efeitos identificados e analisá-los com a evidência de que a empresa inova ao se relacionar com o ambiente (instituições, universidades, governo, outras empresas, fornecedores, cliente, entre outros). A formação de capital social entre a empresa inovadora e os demais atores econômicos envolvidos com o processo de inovação mostra-se necessária para o sucesso do processo de inovação na economia. Nesse sentido, buscase contribuir com a definição de políticas públicas e estratégias empresariais ligadas ao desenvolvimento de mecanismos de promoção de cooperação entre as empresas e entre setores industriais afins, conforme apontam os resultados do modelo verificados em Steingraber \& Gonçalves (2010).

Este artigo é composto de seis seções para desenvolver o objetivo de análise apresentado anteriormente, incluindo-se esta introdução e a conclusão.

A seção dois introduz a teoria Schumpeteriana utilizada. Ela mostra a importância da colaboração da empresa para inovar, visto que a empresa situa-se em um ambiente complexo e muitos atores necessários para a viabilidade do processo de inovação pertencem à esfera social e não apenas à esfera econômica. As empresas percebem que a formação de capital social é essencial para reduzir os riscos e custos da inovação e colaborações e alianças estratégicas se mostram como ferramentas eficientes de cooperação para inovar conforme a 
literatura da Economia Institucional, que se mostrou adaptativa ao arcabouço Schumpeteriano de inovação.

A seção três apresenta o modelo econométrico utilizado. A estimativa da PTF das empresas industriais brasileiras para o ano de 2005 é feita por meio das competências para inovar da empresa (esfera microeconômica) e da cooperação para inovar (esfera mesoeconômica). Os resultados são apresentados na seção quatro.

A seção cinco discute os impactos e sugestões de políticas públicas e estratégias empresariais para inovar relacionadas ao modelo estimado. A seção seis conclui o artigo.

\section{A cooperação para inovar nas empresas}

A fundamentação teórica desse estudo é definida na visão de Teece (1990). O autor mostra que a Economia privilegia a competição ao estudar o processo de inovação. Todavia, a cooperação, entre outras formas de organização de mercado, como verticalização e acordos entre empresas, é igualmente importante na explicação do impacto da tecnologia sobre a economia e poucos estudos sobre a organização intra e interfirmas para inovar foram realizados.

Nesse sentido, a vantagem da grande empresa para inovar se destaca, pois a mesma: i) consegue lidar com gastos em $\mathrm{P} \& \mathrm{D}$, ii) consegue diversificar mais seu portfólio tecnológico em diferentes produtos e oportunidades, iii) consegue controlar mais o mercado e aumentar a rentabilidade da inovação. Justamente as grandes empresas, conforme ilustra a teoria dos jogos em comportamento de mercados não competitivos, são mais propensas a realizar acordos e coordenar as ações e estratégias para inovar. Conforme apontam Dosi et al. (1990) justamente os mercados com competição imperfeita tendem a inovar mais, em função da presença de empresas maiores e formação de monopólios de inovação, o que nos leva a concluir que as empresas e mercados são compelidos naturalmente a cooperar para inovar e não apenas a competir.

Conforme Malerba (1992) a cooperação para realizar P\&D é explicada pela necessidade de acumulação de conhecimento (que é interno e externo). O processo é denominado de learning by firms. Independentemente da visão restrita ao processo de $\mathrm{P} \& \mathrm{D}$, a busca de informação se aplica a todo o processo de inovação da empresa e a presença de cooperação se mostra naturalmente vantajosa e uma estratégia importante para o sucesso da inovação.

A relação entre inovação, cooperação e tamanho da empresa não é vista por muitos autores como direta. Para Adams (1970) as empresas do menor porte podem usar mais a cooperação para inovar em relação às grandes empresas. O autor analisa o mercado dos Estados Unidos e da França e percebe que as empresas francesas cooperam mais para desenvolver projetos de $\mathrm{P} \& \mathrm{D}$ em relação às empresas norte-americanas e conclui que as empresas menores podem cooperar mais para inovar, desde que o ambiente institucional seja favorável, o que acontece na França, assim como em outros países da Europa. A conclusão de Adams (1970) abre caminho para os estudos sobre a cooperação para inovar em sistemas regionais de inovação. Autores como Cooke (1992) e Cooke et al. (1997) analisam a formação e competências dos sistemas regionais de inovação que se mostram estrategicamente atraentes para empresas menores, principalmente de porte médio. 
Percebe-se uma conclusão importante para a cooperação na inovação na linha Schumpeteriana: o tamanho é importante se a empresa é analisada de forma isolada, se a inovação captar o ambiente sistêmico de inovação, os arranjos e sistemas regionais privilegiam as empresas de porte menor para cooperar.Todavia, os incentivos para cooperar na inovação não dependem do tamanho da empresa apenas, mas sim do ambiente institucional no qual a mesma está inserida.

Apesar da relação entre tamanho da empresa e a cooperação para inovar, pode-se destacar alguns limites nesses estudos. A relevância do ambiente institucional, a informalidade da cooperação e o desenvolvimento de competências internas específicas para cooperar no processo de inovação são destacados em outros estudos da própria linha de pesquisa Schumpeteriana, sendo que apenas a segunda consideração depende, em certa medida, do tamanho da empresa.

Primeiramente, Aghion \& Tirole (1990) mostram como os principais estudos sobre o tema consideram apenas indicadores de P\&D para medir o desempenho das empresas, todavia, o correto é pensar no financiador, criador, proprietário e usuário da inovação, em outras palavras, o processo de inovação é mais complexo do que as atividades de P\&D. Outro conjunto de fatores desconsiderados se relaciona com o papel do governo, do financiamento, além do desempenho organizacional do processo. Percebe-se que a cooperação muda de foco quando se considera o processo sistêmico de inovação, a contribuição do tamanho da empresa é apenas uma variável entre outras envolvidas na decisão de cooperar para inovar quando o ambiente é levado em consideração.

Em segundo lugar, Bönte \& Keilbach (2005) mostram a existência de cooperação formal e informal. Os autores mostram que as empresas tendem a desenvolver mecanismos informais de cooperação para inovar. As grandes empresas, com gastos contínuos e consideráveis nos seus departamentos de $\mathrm{P} \& \mathrm{D}$, tendem a usar mecanismos formais de cooperação. Já a informalidade aumenta com a relação entre compradores e vendedores de certa tecnologia (ou recursos) para inovar.

Em terceiro lugar, a empresa que coopera para inovar depende do desenvolvimento de competências específicas. Conforme Alves et al. (2007), as empresas precisam de criatividade para inovar em função da constante adaptação exigida pelo mercado. A criatividade advém da formação de competências multidisciplinares e cooperação (diversidade de atores), coerência (integração e atividades complementares) e interatividade (consistência da relação). Para a estratégia de desenvolvimento de produtos futurísticos (inovações radicais) esse desafio é maior. Faria et al. (2010), ao analisarem a relação entre cooperação e inovação nas empresas de Portugal, mostram que as empresas com maior capacidade de absorção, exportação e intensidade de inovação, participam de algum grupo, apresentam maiores taxas de apropriação e são mais propensas para cooperar para inovar.

A pergunta que surge é: essas competências desenvolvidas dependem do porte da empresa? A resposta pode não ser direta. Empresas maiores podem desenvolver as próprias competências ou buscá-las em outras empresas no mercado doméstico ou internacional e cooperar no desenvolvimento da inovação. Empresas menores podem cooperar na formação das referidas competências com atores institucionais, como universidades e laboratórios públicos.

Nesse momento, a crítica de Aghion \& Tirole (1990) fica mais evidente, pois a cooperação pode estar presente em diferentes momentos do processo 
de inovação, seja na busca por competências para inovar, seja no processo de desenvolvimento da mesma ou na sua fase de comercialização. Identifica-se a falta de uma taxonomia para cooperação, diferentes etapas do processo de inovação envolvem diferentes formas de cooperação. Se a análise considerar a formação de redes de cooperação para $\mathrm{P} \& \mathrm{D}$, as grandes empresas serão apontadas como relevantes, se a análise considerar a cooperação com atores de um sistema regional de inovação, empresas menores apresentarão maior relevância.

A questão que surge é o que é cooperação no processo de inovação?

O entendimento dos diferentes motivos para cooperar para inovar se mostra importante nesse contexto, apesar do reconhecimento da sua ampla e variada generalização, assim como sua consequente falta de padronização ou redução para comportamentos explicativos comuns.

O estudo dos motivos para a empresa cooperar para inovar aproxima à teoria Schumpeteriana da Nova Economia Institucional (NEI). Todavia, conforme esclarecem Oxley \& Silverman (2008), esses motivos são diversos e não é possível formar uma taxonomia definitiva.

A Tabela 1 a seguir sintetiza os motivos de cooperação para inovar nas empresas. Percebe-se que os estudos identificam elementos econômicos (como custos) e não econômicos (acesso à informação) para explicar o comportamento cooperativo na inovação. Esses elementos não econômicos, muitas vezes denominados de forma generalista de instituições, mostram que a inovação é sistêmica e depende de fatores encontrados no ambiente e não restritos ao mercado. ${ }^{1}$

Becker \& Dietz (2004) sintetizam bem os resultados apurados na Tabela 1: a cooperação para inovação depende de fatores microeconômicos (intensidade de $P \& D$, tamanho da empresa) e ambientais (existência de recursos externos, estrutura de mercado e nível tecnológico do setor). ${ }^{2}$ Os resultados empíricos desses autores na indústria alemã mostram que a cooperação para inovar é mais explicada para complementar recursos na fase de P\&D.

Os fatores que explicam a cooperação para inovar estão intensamente relacionados com a $P \& D$, o que explica a razão de essa variável ser utilizada nas análises empíricas sobre inovação, o que privilegiou a conclusão de que o tamanho é importante para cooperar. Os fatores relacionados às competências, como capacidade de obtenção de financiamento, definição de estratégias de inovação, como redução de riscos e incertezas e redução do tempo do processo de inovação ser comercializável, são genéricos e podem igualmente ser relacionados com diferentes tamanhos de empresa em diferentes ambientes institucionais e estruturas de mercado.

\subsection{Problemas do processo de cooperação para inovar}

Até aqui se mostrou que a cooperação no processo de inovação apresenta vantagens para as empresas participantes. Conforme a literatura Institucional, a

\footnotetext{
${ }^{1}$ Não apenas a Economia estuda o comportamento dos agentes econômicos envolvidos no processo de inovação. A Sociologia Econômica, Teoria das Organizações, estudos de Empreendedorismo e Estratégia na Administração são exemplos de áreas afins. A Economia Schumpeteriana se aproximou nos últimos anos da Economia Institucional para entender como as instituições participam deste processo.

${ }^{2}$ Bidault et al. (1998) mostram empiricamente a relação entre empresa e fornecedor no setor automotivo (Estados Unidos, Europa e Japão). Os autores comprovam a complexidade da relação, bem como a sua importância no processo de inovação.
} 
Tabela 1: Motivos para cooperação no processo de inovação

\begin{tabular}{|c|c|c|c|c|}
\hline Becker \& Dietz (2004) & Bönte \& Keilbach (2005) & Faems et al. (2005) & Faria et al. (2010) & Pyka (2002) \\
\hline $\begin{array}{l}\text { Obtenção de financiamento } \\
\text { Redução de incertezas } \\
\text { Redução de riscos } \\
\text { Economias de escala e escopo }\end{array}$ & $\begin{array}{l}\text { Redução de riscos } \\
\text { Alta escala para P\&D } \\
\text { Spillovers de conhecimento } \\
\text { Condições de apropriabili- } \\
\text { dade } \\
\text { Capacidade de absorção } \\
\text { Estrutura organizacional de } \\
\text { P\&D } \\
\text { Dinâmica inovativa da indús- } \\
\text { tria } \\
\text { Complementariedade }\end{array}$ & $\begin{array}{l}\text { Redução de riscos } \\
\text { Redução de custos } \\
\text { Transferência de conheci- } \\
\text { mento codificado e tácito } \\
\text { Presença de recursos de di- } \\
\text { fícil mobilização }\end{array}$ & $\begin{array}{l}\text { Presença de spillovers } \\
\text { Complexidade da inovação } \\
\text { Presença de fluxo externo de } \\
\text { informação }\end{array}$ & $\begin{array}{l}\text { Complementariedade tecnológica } \\
\text { Estratégia de escala global } \\
\text { Redução do tempo entre desco- } \\
\text { berta e introdução da inovação no } \\
\text { mercado } \\
\text { Exploração de novos mercados e } \\
\text { nichos de mercado } \\
\text { Monitoramento da evolução da tec- } \\
\text { nologias e oportunidades }\end{array}$ \\
\hline
\end{tabular}


cooperação pode apresentar problemas relacionados ao comportamento oportunista, a presença de custos de transação, racionalidade limitada dos agentes e custos de agência. Becker \& Dietz (2004) afirmam que a cooperação para inovar apresenta problemas de coordenação de rotinas organizacionais, de combinação entre ativos e recursos complementares, de fixação de preços de ativos intangíveis (por exemplo, know-how) e regulação da apropriação.

Baumol (1992) mostra que a empresa imitadora pode copiar a inovação e concorrer com ela por meio de engenharia reversa, contratação de empregados da empresa inovadora ou espionagem. Para tanto, existe um mercado de venda de informações, equipamentos e treinamento para imitar a inovação. Em outras palavras, a empresa pode cooperar com outras empresas para reduzir o hiato tecnológico em relação aos líderes de mercado e concorrer com eles.

A relação entre cooperar e competir é próxima e complexa. Bó (2005) mostra que essa relação advém da "tensão entre os incentivos privados que encorajam o comportamento oportunista e o bem público que vem da cooperação". Essa tensão fica evidente no estudo de Jorde \& Teece (1990), onde a característica de bem público da inovação e a cooperação envolvida no seu processo levantam o problema do carona (free rider) - que se aproxima da ideia de comportamento oportunista da teoria Institucional. Nooteboom (2008) defende que a saída para lidar com o dilema da cooperação é avançar no entendimento dos limites institucionais e comportamentais do processo de inovação e a construção de uma agenda de governança para a cooperação.

Outro problema da cooperação para inovar apresentado em Jorde \& Teece (1990) é a redução da diversidade. Se por um lado a cooperação reduz custos e riscos do processo de inovação, por outro, ela reduz a diversidade de recursos e ideias duplicados. A diversidade explica a dinâmica de evolução da inovação, na medida em que ideias diferentes são reduzidas, o progresso tecnológico pode apresentar a centralização em poucos paradigmas tecnológicos. Mowery (1998) mostra a tendência de colaboração de P\&D entre empresas, universidades e laboratórios públicos (governo) como a principal estratégia de desenvolvimento de inovação em curso atualmente. O estreitamento da cooperação centralizou os gastos na fase de desenvolvimento e menos na fase de pesquisa. Nitidamente, os esforços de cooperação se focaram no resultado final do processo de inovação - que é sua fase comercial - e com menor intensidade na fase de pesquisa que abre novas perspectivas de crescimento de longo prazo.

A redução da diversidade se aplica na maior homogeneidade dos recursos da empresa. Fato que restringe a formação de competências para inovar (Penrose 1959, Chandler 1977, Nelson \& Winter 1982). O estreitamento da diversidade das competências da empresa, conforme Mowery et al. (1996) e Mowery (1998), restringirá futuramente a própria cooperação para inovar, visto que as competências tecnológicas da empresa e as redes sociais explicam a formação de alianças (cooperação). A cooperação entre empresas aumenta a probabilidade de desenvolver novos conhecimentos tecnológicos. ${ }^{3}$ O sucesso comercial da cooperação no processo de desenvolvimento justifica a definição de políticas públicas para a pesquisa, seja na esfera de políticas educacionais e formação de conhecimento em C\&T dentro da visão de inovação sistêmica

\footnotetext{
${ }^{3}$ Os referidos estudos analisaram o número de patentes como proxys do progresso tecnológico.
} 
(por exemplo, o Sistema Nacional de Inovação - SNI). Nesse sentido, Nooteboom (2008) define a colaboração para inovar em três níveis: local, nacional e supranacional. A dicotomia entre o local e o global na definição de estratégias de cooperação pode ser acompanhada nas discussões de Porter (1998) e Porter (2000). Apesar de este não ser o objeto de discussão deste artigo, aponta-se a importância da agenda de discussão de aglomerações e inovação sistêmica que permeiam a ideia de cooperação, como os Sistemas Nacional, Setorial, Regional e Tecnológico de inovação (Edquist 1997).

\subsection{A empresa em rede}

Como apresentado anteriormente, se o estudo da cooperação privilegiar a empresa isoladamente o tamanho explica grande parte dessa dinâmica. Os resultados de Cassiman \& Veugelers (2002) mostram que as empresas com maior capacidade de apropriabilidade e formação (absorção) de spillovers (informação de patentes, conferências e feiras) apresentam maior probabilidade de cooperar om universidades, centros de pesquisa e laboratórios, mas não afeta a probabilidade cooperação com fornecedores e distribuidores. Cassiman \& Veugelers (2005) mostram evidências de que as empresas que realizam cooperação apresentam capacidade de absorção alta, são empresas maiores e os recursos são com lementares. Portanto, a cooperação aumenta com a intensidade de $\mathrm{P} \& \mathrm{D}$, capital humano e tamanho da empresa, mas não com o market share. Ele é positivo, mas empresas com maior poder de mercado não cooperam mais que as outras (Negassi 2004).

Fritsch \& Lukas (2001) analisam a cooperação com fornecedores, distribuidores e instituições de pesquisa públicas e mostram que as empresas são maiores e apresentam taxas de gasto em P\&D mais elevadas. Os autores mostram também que setorialmente e regionalmente, a cooperação para inovar depende do número de participantes e os resultados são mais tímidos.

Fritsch \& Franke (2004) analisam a cooperação dentro do processo de aglomeração. Esta pode ser vista em uma determinada área de conhecimento (mesma indústria) e explicada pelas diferenças de produtividade na atividade de $P \& D$. A cooperação em $P \& D$ tende a aumentar essa produtividade e a presença de instituições públicas de pesquisa conduz a esse mesmo aumento de produtividade. Nesse sentido, a presença do governo acelera a cooperação entre empresas dentro do território ou de uma indústria para inovar.

Percebe-se uma diferenciação na estratégia de cooperação para inovar de acordo com o objetivo da empresa, pois conforme mostram Lhuillery \& Pfister (2009), existe a cooperação vertical (fornecedores, distribuidores). Ela possui menor chance de falhas de cooperação em relação à cooperação horizontal (concorrentes e organizações públicas de pesquisa). Na cooperação vertical os motivos da realização de uma aliança são mais importantes, como as restrições governamentais (importante para internacionalização de empresas), a necessidade da empresa não possuir todos os recursos necessários para manter a vantagem competitiva na sua indústria (ou segmento), além do aumento da escala e escopo (Oxley \& Silverman 2008).

A literatura da NEI mostra que as empresas são estimuladas a cooperar para reduzir seus custos de transação. A inovação entra como incerteza pela tecnologia, o que leva a um modelo de estrutura híbrida entre os extremos de usar o mercado e a integração vertical (Pyka 2002). 
Essa constatação pode ser importante para o futuro da linha de pesquisa das escolas Schumpeteriana e Institucional. Enquanto a escola Institucional verifica a relação do desenvolvimento no processo de inovação, pois este afeta diretamente as relações de mercado da empresa e sua formação em rede, a escola Schumpeteriana verifica a cooperação na fase de pesquisa. Conforme Tether (2002), essa fase depende do lançamento de produtos novos no mercado, a necessidade de cooperação é maior para as empresa que lançam produtos novos no mercado e menor para as empresas que lançam produtos novos para elas apenas. Portanto, o grau de novidade depende do esforço de inovação, e este é determinado pelo esforço de cooperação da empresa que em última análise depende da construção das competências internas para inovar.

Percebe-se a necessidade de cooperação da empresa na sua rede de produção e distribuição de bens e serviços, sob a forma vertical. A resposta da empresa a essa cooperação pode estar formalizada na forma de inovação e ganhos de produtividade. Por outro lado, a análise Schumpeteriana investiga mais o processo horizontal de cooperação que relaciona a empresa inovadora com as instituições envolvidas no processo de inovação, como governo, centros de pesquisa e universidades.

O modelo empírico desenvolvido na próxima seção apresenta a relação entre a produtividade da empresa, suas competências internas para inovar e a cooperação vertical para inovar.

\section{O modelo}

Essa estimativa, assim como o modelo de Steingraber (2009), considera a produtividade total dos fatores da empresa $i$ no setor $j\left(P T F_{i j}\right)$ como função das competências para inovação na empresa $i$ no setor $j\left(C_{i j}\right)$ no ano de 2005:

$$
P T F_{i j}=\alpha_{1}+\alpha_{2} C_{i j}+e_{i j}
$$

O vetor $C_{i j}$ com as competências para inovação na empresa é composto pelas seguintes variáveis: mão de obra inovadora, pessoal ocupado com terceiro grau, renda média do trabalhador, tempo médio de escolaridade do trabalhador, número de pedidos de patentes, share, número de empregados e valor das exportações e das importações. Essas competências para inovação são a fonte original do início do processo de inovação na empresa (Penrose 1959, Chandler 1977, Nelson \& Winter 1982) e explicam o desempenho da PTF, já que esta é tautológica, mas permite a comparação entre diferentes empresas nos setores industriais. ${ }^{4}$

A PTF é calculada pelo método de Resíduo de Abramovitz (1956), conforme defende Antonelli (2003). Dessa forma, a PTF é calculada como a diferença da taxa de mudança do valor do produto, descontado o valor despendido pelos fatores, agora vistos como a taxa de mudança dos gastos com trabalho e o investimento (mudança no estoque de capital da empresa). A determinação da PTF é dada como:

\footnotetext{
${ }^{4} \mathrm{O}$ modelo analisa as empresas nos setores industriais, fato que evita a comparação entre produtividade de empresas de setores diferentes, o que não é recomendável, apesar de a variável ser monetária e permitir tal procedimento, pois o uso econômico dos fatores e das competências microeconômicas divergir de setor para setor.
} 


$$
P T F=d Y-\left(\frac{d y}{d k}\right) d K-\left(\frac{d y}{d l}\right) d L
$$

onde $d Y$ é a variação do produto (receita líquida de vendas). As derivadas $\left(\frac{d y}{d k}\right)$ e $\left(\frac{d y}{d l}\right)$ são respectivamente as elasticidades do produto em relação ao capital e ao trabalho. Já $d K$ e $d L$ indicam a variação do capital ${ }^{5}$ (investimento) e do trabalho. ${ }^{6}$ A estimativa da equação (2) foi realizada do ano 2004 para o ano 2005, em função da equação se apresentar como uma derivada (taxa de mudança). A vantagem do uso da equação (2) reside na dinâmica de uso de uma taxa de mudança (diferencial) e não de logaritmos, como uma função Cobb-Douglas, além de as derivadas parciais não representarem a contribuição marginal do capital e do trabalho no produto, mas sim a participação relativa dos mesmos no produto. Por fim, a variação do capital, calculada como investimento, facilita a determinação estatística da variável, visto que a PIA não dispõe de uma variável de computação do valor do capital da empresa. A variação de capital (investimento) foi calculada como o valor despendido pela empresa na aquisição de ativos (maquinaria, imóveis, equipamentos e outros ativos imobilizados na PIA) menos as baixas no valor dos mesmos ativos. A variação no trabalho mostra a alteração na estrutura de gastos com a folha de pagamentos (salários, remunerações, benefícios, INSS e outros valores computados na categoria despesa salarial da PIA).

As variáveis que explicam as competências internas da empresa são formadas por meio da base RAIS - Relatório Anual de Informações Sociais do Ministério do Trabalho (renda, escolaridade, tempo de estudo, número de empregados, ${ }^{7}$ mão de obra inovadora, percentual de trabalhadores com $3^{\circ}$ de escolaridade na empresa, share, experiência do trabalhador na empresa e experiência do trabalhador no setor - estas duas últimas não significativas estatisticamente), ${ }^{8}$ da PIA (share, turnover de capital, acesso a insumos interna-

${ }^{5} \mathrm{O}$ investimento é calculado como a variação do estoque de capital de 2004 para 2005. O estoque de capital não existe na PIA e é calculado como o soma dos ativos da empresa e inclui: terrenos e edificações, máquinas e equipamentos industriais, meios de transporte, outras aquisições (móveis, microcomputadores, etc.) que estão nas variáveis 0048, 0049 e 0050 da PIA 2005.

${ }^{6}$ A variação salarial é calculada como diferença de 2004 para 2005 e inclui a variável 0023 (salários, retiradas e outras remunerações) menos as variáveis 0024 (contribuições para a previdência social), 0025 (FGTS), 0026 (contribuições para previdência privada), 0027 (indenizações trabalhistas e por dispensa incentivada) e 0028 (benefícios concedidos aos empregados).

${ }^{7} \mathrm{O}$ número de trabalhadores empregados no dia 31 de dezembro de 2005 é denominado de número de contratos no modelo.

${ }^{8} \mathrm{~A}$ renda mede a renda média mensal do trabalhador em Reais; a escolaridade mede o tempo de estudo médio do trabalhador; o número de empregados mede o número médio anual de empregados da empresa; a mão de obra inovadora contabiliza o número de profissionais relacionados à atividade de inovação e é formada pelas variáveis da PINTEC 2005: químicos, físicos e assemelhados (67 - dedicação integral e 73 - dedicação parcial), engenheiros, arquitetos e assemelhados (68 - dedicação integral e 74 - dedicação parcial), médicos, cirurgiões dentistas, veterinários, enfermeiros e assemelhados (69-dedicação integral e 75 - dedicação parcial), biologistas, bacteriologistas, farmacologistas e assemelhados (70 - dedicação integral e 76 - dedicação parcial), estatísticos, matemáticos, analistas de sistemas e assemelhados ( 71 — dedicação integral e 77 - dedicação parcial), outros (72 - dedicação integral e 78 - dedicação parcial); o percentual de trabalhadores com o terceiro grau é medido em relação ao número total de empregados da empresa: $\frac{\text { profissionais com o terceiro grau na empresa } i}{\text { total de empregados na empresa } i}$ o share (emprego) é mensurado como: $\frac{\text { contratos da empresa } i \text { no setor } j}{\text { contratos do setor } j}$ e é equivalente para a versão do share para a receita da PIA em Reais; o tempo de experiência do trabalhador na empresa é o tempo de carteira assinada na empresa e 
cionais e a própria PTF), ${ }^{9}$ SECEX (valor das importações e exportações, em dólares) ${ }^{10}$ e INPI (número de pedidos de patentes). ${ }^{11}$

O share da PIA foi calculado em função da participação da receita líquida de vendas da empresa em função da receita líquidas de vendas do setor. Já o share da RAIS considera a participação na empresa no emprego total do setor. Ambas as variáveis foram significativas nas estimativas realizadas, todavia, optou-se pelo share da RAIS, visto que as demais variáveis da PIA (insumos internacionais e turnover de capital) não foram estatisticamente significativas na estimativa dos efeitos fixos e foram eliminadas do modelo. ${ }^{12}$

A variável de controle setorial (Cooperação para Inovar) pertence à base PINTEC $^{13}$ e identifica a presença de cooperação da empresa inovadora com fornecedores, distribuidores, consumidores e outras empresas. Qualquer uma das afirmativas positivas é definida como um (1), se a empresa não cooperou o valor gerado é zero (0). Nesse sentido, não se faz distinção do tipo de cooperação desenvolvida pela empresa, se a mesma é a jusante ou a montante. É importante destacar que essa variável capta apenas a cooperação com outras empresas e consumidores e não a cooperação com universidades e governo para inovar; trata-se de uma cooperação ao longo da cadeia produtiva da empresa inovadora.

Essa variável é considerada no setor, apesar de ser uma variável no nível da empresa na PINTEC, todavia, a regressão hierárquica estabelece níveis. A hipótese assumida para se colocar a cooperação no nível do setor e não da empresa é a presença de características setoriais no processo de inovação, como em Malerba (2002) e Breschi \& Malerba (1997). Nesse sentido, a cooperação para inovar estabelece que a empresa necessita de instituições (governo, universidades) e da cadeia produtiva (vertical), como fornecedores, distribuidores, clientes, entre outros e que estão na esfera setorial (industrial). Portanto, a cooperação para inovar é calculada setorialmente, como uma média por indústria e que impacta (multiplica) a esfera microeconômica (as empresas inovadoras). Na regressão, as estimativas são feitas na mesma equação (ver equação 5 a seguir), todavia, estima-se primeiramente o segundo nível (cooperação para inovar) para que este se relacione com as características individuais

no setor contempla todo o período de carteira assinada em empresas no setor (mesma atividade industrial).

${ }^{9} \mathrm{O}$ share da PIA é calculado de maneira equivalente ao share da RAIS (ver nota anterior) e utiliza a receita líquida total - variável 0017 da PIA 2005; o turnover de capital é contabilizado como a participação do investimento em máquinas e equipamentos em relação ao total de investimento na empresa no ano e corresponde a variável de capital (ver nota de rodapé 5); o acesso aos insumos internacionais mede se empresa é importadora de insumos e a participação relativa dos mesmos no consumo total de insumos.

${ }^{10}$ Os valores em dólares foram convertidos pela cotação de $\mathrm{R} \$ 2,45$ que corresponde ao valor médio do câmbio pelo IPEADATA e foi utilizado em outros modelos econométricos da equipe do IPEA que cuida do acesso ao banco de dados do IBGE no Rio de Janeiro.

${ }^{11}$ A variável considera o pedido de patente registrado no INPI pela empresa nos anos de 2003, 2004 e 2005, em função do pequeno número de empresas com depósitos de patentes no ano de 2005 e por se tratar de uma variável de ciclo longo.

${ }^{12}$ A escolha do share RAIS e não do share da PIA é arbitrária, pois as duas variáveis apontam para a mesma interpretação: o tamanho relativo da empresa no setor.

${ }^{13}$ A cooperação para inovar é a variável 116 da PINTEC 2005 e pergunta se a empresa cooperou para inovar com as opções 1 (sim) e 2 (não). A questão esclarece que o apoio para inovar é "a participação ativa em projetos conjuntos de P\&D e outros projetos de inovação com outra organização (empresa ou instituição). Isso não implica, necessariamente, que as partes envolvidas obtenham benefícios comerciais imediatos. A simples contratação de serviços de outra organização, sem a sua colaboração ativa, não é considerada cooperação." (IBGE 2004). 
da empresa (primeiro nível) e expliquem a PTF.

A escolha dessa variável restringe o processo de cooperação para as atividades de desenvolvimento. Claramente, o processo de pesquisa significa a aproximação da empresa com atores institucionais, como universidades e centros de pesquisa. Ver Steingraber \& Gonçalves (2010) para esta última relação de cooperação.

O modelo é estimado pelo método de regressão multinível (ou regressão hierárquica). Para tanto, o segundo nível com a variável de controle setorial Cooperação para Inovar $\left(S_{j}\right)$ no setor $j$ é substituída na equação do primeiro nível e, dessa forma temos:

$$
\alpha_{s}=\beta_{1}+\beta_{2} S_{j}+e_{j}
$$

onde os parâmetros estimados da primeira equação $\left(\alpha_{s}\right)$ são explicados por um termo independente $\left(\beta_{1}\right)$ que é a PTF média da indústria brasileira e a variável setorial de Cooperação $S_{j}$. Os termos independentes no modelo representam a PTF média do nível acima, em função das variáveis serem centralizadas na média, dessa forma, $\alpha_{1}$ é a PTF do setor $j$ e a PTF da empresa $i$ no seu setor é explicada como um desvio dessa média em função das competências para inovação da referida empresa. Já $\beta_{1}$ é a PTF média da indústria brasileira e a PTF do setor é o desvio desta média em função da Cooperação para Inovar de cada setor. Nesse sentido, as variáveis estimadas apresentam desvios positivos (contribuição acima da média na PTF do setor e da indústria respectivamente), ou desvios negativos (contribuição abaixo da média na PTF do setor e da indústria respectivamente).

Substituindo a equação (3) em (1), temos:

$$
P T F_{i j}=\beta_{1}+\beta_{2} S_{j}+e_{j}+\left(\beta_{1}+\beta_{2} S_{j}+e_{j}\right) C_{i j}+e_{i j}
$$

Reagrupando, temos:

$$
P T F_{i j}=\beta_{1}+\beta_{1} C_{i j}+\beta_{2} S_{j}+\beta_{2} S_{j} C_{i j}+e_{j} C_{i j}+e_{j}+e_{i j}
$$

onde a produtividade da empresa $\left(P T F_{i j}\right)$ é explicada pela produtividade do setor $\left(\beta_{1}\right)$, pelos efeitos fixos do setor $\left(\beta_{2} S_{j}\right)$, os efeitos fixos da empresa $\left(\beta_{1} C_{i j}\right)$ e os efeitos fixos na empresa e no setor $\left(\beta_{2} S_{j} C_{i j}\right)$ e os efeitos aleatórios $\left(e_{j} C_{i j}\right)$ e o erro total, composto pela soma do erro na empresa $\left(e_{i j}\right)$ e no setor $\left(e_{j}\right)$.

O modelo multinível é estimado por meio da equação (5).

A distribuição da Cooperação para Inovar é apresentada na Figura 1.

A Figura 1 mostra que a maioria das empresas industriais brasileiras que inovaram recebeu algum tipo de apoio externo para inovar, todavia, esse apoio é, em média, de baixa importância, ${ }^{14}$ perto de $20 \%$ das empresas não recebeu apoio, e $77 \%$ apontou como um (1 - importância baixa) o grau de importância da cooperação com outras empresas, fornecedores, distribuidores e consumidores para inovar.

Além da distribuição, o modelo simples (apenas a PTF em função do termo independente - a PTF nos setores) foi estimado. O resultado do mesmo mostra a covariância dos parâmetros, ou seja, quando do modelo pode ser relacionado à diferença entre empresas e entre setores em relação à produtividade.

\footnotetext{
${ }^{14}$ A PINTEC considera de 0 (não cooperou) até 4 o grau de importância da cooperação.
} 


\section{Cooperação para Inovar}

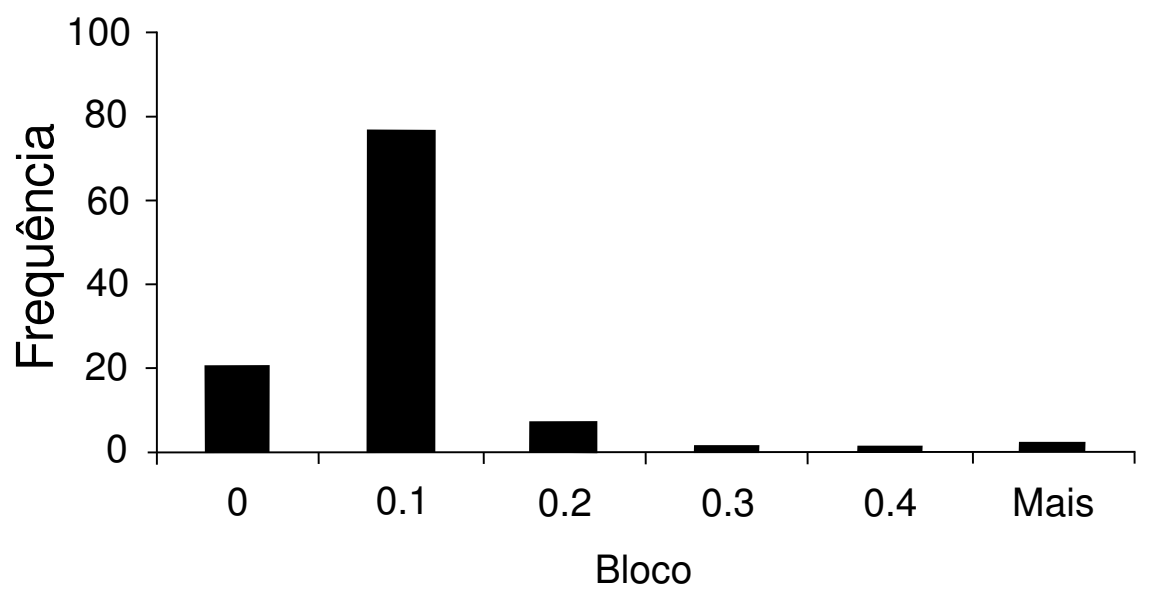

Fonte: O autor com os microdados do IBGE.

Figura 1: Distribuição da frequência da cooperação para inovar por setor na indústria Brasileira no ano de 2005

Os resultados estimados mostram que a covariância entre os setores explica $99 \%$ da produtividade da empresa, já as diferenças entre as empresas no mesmo setor explicam apenas $1 \%$ da produtividade considerada. Esse resultado mostra que o controle setorial é necessário para explicar a PTF das empresas, visto que dentro do mesmo setor, as empresas apresentam uma distribuição muito homogênea de suas produtividades, todavia, as empresas apresentam valores diferentes entre setores diferentes.

Como os setores apresentam diferenças de produtividade e diferenças nos níveis de cooperação para inovar, o modelo estimado explora se essas diferenças setoriais são dependentes. Esta é a hipótese a ser explorada pelo modelo: as diferenças de cooperação entre setores se refletem nas diferenças de produtividade entre os mesmos.

A estimativa realizada agrupa as empresas por setores (CNAE 1.0). ${ }^{15}$ Os agrupamentos setoriais endogenamente identificam a Cooperação para Inovar, portanto, essa variável é interpretada setorialmente e relacionada com a PTF e as competências microeconômicas para inovar das empresas industriais brasileiras no ano de 2005.

Os resultados estimados são apresentados na próxima seção.

\section{Estimativas}

Os valores estimados da equação (5) foram obtidos pelo método de Máxima Verossimilhança (MV), conforme argumenta Hox (2002). O modelo original de Steingraber (2009) seguiu esta metodologia, em função dos estimadores por Mínimos Quadrados Ordinários (MQO) serem inconsistentes na regressão multinível.

\footnotetext{
${ }^{15}$ Uma regressão hierarquica capta endogenamente a influência de agrupamentos da variável considerada. Nesse sentido, o cálculo de uma produtividade média não está errado, mas desconsidera as diferenças existentes entre os setores industriais.
} 
As estimativas dos efeitos fixos e aleatórios são apresentadas nas tabelas (2) e (3).

Tabela 2: Estimativa dos efeitos fixos na PTF da empresa

\begin{tabular}{|c|c|c|}
\hline Variável & Estimativa & $\rho$ \\
\hline Intercepto & $\begin{array}{l}3.191 .613 \\
(2,76)\end{array}$ & 0,0058 \\
\hline Mão-de-obra inovadora & $\begin{array}{c}509.119 \\
(14,21)\end{array}$ & $<0,0001$ \\
\hline Percentual de trabalhadores com $3^{\circ}$ & $\begin{array}{c}-32.126 \\
(-3,32)\end{array}$ & 0,0009 \\
\hline Renda média do trabalhador & $\begin{array}{c}1.667,95 \\
(1,95)\end{array}$ & 0,0516 \\
\hline Tempo de estudo médio & $\begin{array}{c}1.612 .911 \\
(4,4)\end{array}$ & $<0,0001$ \\
\hline Número de pedidos de patentes & $\begin{array}{c}-763.195 \\
(-9,33)\end{array}$ & $<0,0001$ \\
\hline Share & $\begin{array}{c}-4,98 E 8 \\
(-11,11)\end{array}$ & $<0,0001$ \\
\hline Contratos & $\begin{array}{c}11.618 \\
(10,3)\end{array}$ & $<0,0001$ \\
\hline Valor exportado & $\begin{array}{c}-0,07382 \\
(3,92)\end{array}$ & $<0,0001$ \\
\hline Valor importado & $\begin{array}{c}0,5909 \\
(18,22)\end{array}$ & $<0,0001$ \\
\hline Cooperação no setor & $\begin{array}{c}2.493 .435 \\
(0,03)\end{array}$ & 0,9771 \\
\hline Mão-de-obra inovadora ${ }^{*}$ Cooperação no setor & $\begin{array}{c}15.912 .193 \\
(40,88)\end{array}$ & $<0,0001$ \\
\hline Valor exportado ${ }^{*}$ Cooperação no setor & $\begin{array}{c}0,3489 \\
(2,17)\end{array}$ & 0,0299 \\
\hline Valor importado ${ }^{\star}$ Cooperação no setor & $\begin{array}{c}49.868 \\
(22,1)\end{array}$ & $<0,0001$ \\
\hline Percentual de trabalhadores com $3^{\circ *}$ Cooperação no setor & $\begin{array}{l}-3.691 .573 \\
(-39,14)\end{array}$ & $<0,0001$ \\
\hline Renda média do trabalhador ${ }^{\star}$ Cooperação no setor & $\begin{array}{c}-56.395 \\
(-6,23)\end{array}$ & $<0,0001$ \\
\hline Tempo médio de estudo*Cooperação no setor & $\begin{array}{c}-64.510 .000 .000 \\
(-6,67)\end{array}$ & $<0,0001$ \\
\hline Número de pedidos de patentes ${ }^{\star}$ Cooperação no setor & $\begin{array}{c}52.460 .059 \\
(35,43)\end{array}$ & $<0,0001$ \\
\hline Share ${ }^{\star}$ Cooperação no setor & $\begin{array}{c}41.482 .000 .000 .000 \\
(9,03)\end{array}$ & $<0,0001$ \\
\hline-2 Res Log Likelihood & 1.001 .045 & \\
\hline AIC (smaller is better) & 1.001 .049 & \\
\hline AICC (smaller is better) & 1.001 .049 & \\
\hline BIC (smaller is better) & 1.001 .054 & \\
\hline
\end{tabular}

Valor da estatística t entre parênteses. ${ }^{*}$ Indica multiplicação entre as variáveis. Fonte: $\mathrm{O}$ Autor com os microdados do IBGE/IPEA.

O primeiro resultado visível na Tabela 2 é o impacto positivo da PTF do setor sobre a PTF da empresa, visto por meio do intercepto (termo independente). Esse valor mostra que as empresas ganham produtividade em função do desempenho setorial. Já em relação ao impacto da Cooperação para Inovação no setor sobre a produtividade das empresas, o efeito isolado é não estatisticamente significativo. $\mathrm{O}$ valor não significativo mostra que a PTF das empresas não muda em relação à média da indústria brasileira se o setor apresenta mais ou menos cooperação para inovar. O impacto verificado na cooperação é percebido sobre as competências para inovação das empresas, o que nos mostra que não é apenas a simples presença de cooperação que gera ganhos de produtividade, mas sim, o desenvolvimento de competências para inovar que conduz ao aprendizado no setor (concorrentes, distribuidores, consumidor, fornecedores). 
Esse resultado mostra que as políticas públicas para inovação devem se orientar em dois pilares para promover o processo de inovação e geração de ganhos de produtividade. A primeira é a construção de capital social, ou seja, a cooperação para inovar por meio da interação com o ambiente (no caso analisado, a cadeia produtiva). A segunda é o conjunto de competências para inovar nas empresas, pois sem as mesmas torna-se irrelevante incentivar apenas a cooperação no setor industrial, pois a empresa necessita apresentar ex ante as habilidades e competências para interagir com o setor para aprender ou aprimorar o processo de inovação. Discute-se mais detalhadamente esse ponto adiante.

Considerando-se os efeitos fixos da empresa (o impacto das competências para inovar), percebem-se dois comportamentos. Primeiramente, as variáveis que contribuem para o ganho de produtividade nas empresas acima da média (sinal estimado positivo), são: a mão de obra inovadora, a renda e a escolaridade médias do trabalhador, o número de contratos e a importação. $\mathrm{O}$ segundo grupo é formado pelas competências para inovação que contribuem com ganhos de produtividade abaixo da média da indústria brasileira, estas competências são: a presença de trabalhadores com $3^{\circ}$, o número de patentes, a participação de mercado (share) e as exportações.

Quando as competências para inovar são analisadas juntamente com o impacto setorial da cooperação para inovar, o modelo apresenta dois grupos de comportamento. As variáveis que mudam de sinal e as variáveis que mantêm o sinal inalterado em relação ao nível da empresa.

Considerando-se as variáveis que mantêm o sinal, verifica-se que a mão de obra inovadora e as importações mantêm o impacto positivo nos ganhos de produtividade na empresa e no setor acima da média, já a presença de mão de obra com $3^{\circ}$ completo impacta os ganhos de produtividade abaixo da média na empresa e no setor. Esses dados estimados mostram que a simples presença de mão de obra qualificada (titulação) não significa aumento na capacidade de inovação e geração de ganhos de produtividade na empresa. $\mathrm{O}$ objetivo dessa mão de obra é desempenhar tarefas organizacionais e administrativas que não estão relacionadas diretamente à inovação. Já a mão de obra dedicada à inovação impacta o aumento da produtividade na empresa e no setor acima da média. Esse resultado mostra que a simples contratação de mão de obra qualificada não significa capacidade de absorção de conhecimento e geração de inovações nas empresas industriais brasileiras, pois seu impacto na produtividade está relacionado à presença de uma estratégia de inovação na empresa.

O segundo grupo de variáveis é o das que mudam de sinal. Primeiramente, a renda e o estudo médios do trabalhador e o número de contratos impactam a produtividade da empresa acima da média, mas no setor o desempenho das mesmas, o impacto é abaixo da média. Esse resultado mostra que o tamanho da empresa e as características de ganhos de renda e de escolaridade dos trabalhadores são relevantes para as empresas, mas setorialmente a presença de cooperação para inovar não é sensível a essas variáveis. Já o número de patentes, o share e as exportações não são tão importantes para as empresa como são setorialmente para explicar os ganhos de produtividade nas empresas em relação à presença de cooperação.

Os resultados mostram que algumas competências para inovar são mais importantes na explicação dos ganhos de produtividade das empresas industriais quando o setor onde as mesmas estão é cooperativo para inovar. Outras 
competências são mais sensíveis na esfera microeconômica da inovação. Esses resultados suportam a ideia de que o processo de inovação é sistêmico e envolve as competências microeconômicas para inovar, o ambiente setorial, bem como a formação de capital social entre as empresas e os demais atores econômicos e sociais para viabilizar o processo de inovação.

Considerando-se os efeitos aleatórios do modelo, os resultados estimados mostram quais são os setores onde os ganhos de produtividade são mais sensíveis à presença de cooperação. Esses resultados são apresentados na Tabela 3 a seguir.

Tabela 3: Estimativa dos efeitos aleatórios na PTF da empresa

\begin{tabular}{|c|c|c|}
\hline Setor & Estimativa & $\rho$ \\
\hline 131 & 32.400 .000 .000 .000 & $<0,0001$ \\
\hline 151 & $\underset{(2,76)}{5.520 .000 .000 .000}$ & 0,0057 \\
\hline 152 & $-484 . \underset{(1,88)}{000.000 .000}$ & 0,0598 \\
\hline 153 & $\begin{array}{c}-1,07 E 9 \\
(8,73)\end{array}$ & $<0,0001$ \\
\hline 154 & $\underset{(1,91)}{3.270 .000 .000 .000}$ & 0,0560 \\
\hline 159 & -426.000 .000 .000 & 0,0677 \\
\hline 160 & $\underset{(2,15)}{7.480 .000 .000 .000}$ & 0,0316 \\
\hline 223 & $\underset{(2,47)}{4.090 .000 .000 .000}$ & 0,0135 \\
\hline 232 & 3.290 .000 .000 .000 & 0,0447 \\
\hline 241 & -341.000 .000 .000 & 0,0023 \\
\hline 245 & $\underset{(4,07)}{3.790 .000 .000 .000}$ & $<0,0001$ \\
\hline 246 & -353.000 .000 .000 & 0,0002 \\
\hline 272 & -573.000 .000 .000 & $<0,0001$ \\
\hline 273 & $\underset{(1,8)}{4.840 .000 .000 .000}$ & 0,0713 \\
\hline 274 & -729.000 .000 .000 & 0,0220 \\
\hline 293 & -1.010 .000 .000 .000 & 0,0008 \\
\hline 298 & $-\underset{(3,80)}{-472.000 .000 .000}$ & 0,0001 \\
\hline 341 & -188.000 .000 .000 & 0,0466 \\
\hline 342 & $\underset{(5,14)}{5.150 .000 .000 .000}$ & $<0,0001$ \\
\hline 353 & -3.010 .000 .000 .000 & $<0,0001$ \\
\hline
\end{tabular}

Valor da estatística t entre parênteses. Fonte: $\mathrm{O}$ autor.

As informações estimadas na Tabela 3 mostram que vinte setores são estatisticamente significativos na influência do setor sobre a PTF das empresas 
industriais. Esses setores apresentam diferenças da média industrial nacional, os demais setores (109 no total), ou $81,65 \%$ dos setores industriais, apresentam o mesmo valor de produtividade da média da indústria brasileira. Os vinte setores com diferenças da média representam 18,35\% dos setores industriais brasileiros, onde onze (11) setores apresentam ganhos de produtividade abaixo da média da indústria brasileira (sinal estimado negativo) e nove (9) setores apresentam ganhos de produtividade acima da média nacional (sinal estimado positivo). Esses setores representam 10,10 e 8,25\%, respectivamente, dos setores industriais brasileiros considerados na regressão estimada.

Os seguintes setores apresentaram ganhos de produtividade abaixo da média: processamento, preservação e produção de conservas de frutas, legumes e outros vegetais (152), produção de óleos e gorduras vegetais e animais (153), fabricação de bebidas (159), fabricação de produtos químicos inorgânicos (241), fabricação de defensivos agrícolas (246), siderurgia (272), metalurgia dos metais não ferrosos (274), fabricação de tratores e de máquinas e equipamentos para a agricultura, avicultura e obtenção de produtos animais (293), fabricação de eletrodomésticos (298), fabricação de automóveis, camionetas e utilitários (341) e construção, montagem e reparação de aeronaves (353).

Os setores com ganhos de produtividade acima da média nacional são: extração de minério de ferro (131), abate e preparação de produtos de carne e de pescado (151), laticínios (154), fabricação de produtos de fumo (160), reprodução de materiais gravados (223), fabricação de produtos derivados do petróleo (232), fabricação de produtos farmacêuticos (245), fabricação de tubos, exceto em siderurgias (273) e fabricação de caminhões e ônibus (342).

\section{Discussão}

Os resultados estimados são robustos com o conceito Schumpeteriano de inovação sistêmica Edquist (1997), principalmente, o de Sistemas Setoriais de Inovação (SSI) Breschi \& Malerba (1997) e Malerba (2002). A cooperação para inovar é definida no ambiente setorial e impacta as competências para inovar da empresa. Estas últimas explicam o desempenho da PTF das empresas industriais.

Percebe-se a divisão entre fatores micro e mesoeconômicos sobre a produtividade da empresa. Tal resultado sustenta o debate sobre a Política Industrial Schumpeteriana de resultado, com políticas públicas para promover a inovação que se adaptem as diferentes realidades estruturais das indústrias e das empresas.

Outro resultado plausível é amparado no debate de Nelson \& Sampat (2001) sobre a importância do capital social no processo de inovação. A definição de políticas públicas para incremento do processo de inovação deve pensar a formação de capital social entre a empresa e os atores econômicos do setor. Steingraber \& Gonçalves (2010) ampliam esse resultado para os atores institucionais, como governo, universidades, centros de pesquisa e laboratórios públicos. De forma contundente, percebe-se a necessidade de articulação entre a empresa inovadora e o ambiente. Como os resultados do modelo estimado sugerem, a empresa deve desenvolver competências específicas para a articulação com os demais atores do ambiente (sejam eles econômicos ou 
sociais), por outro lado, essas competências dependem em grande medida da estrutura de cada setor.

Os fatores microeconômicos que formam as competências para inovar nas empresas estão ligados à presença de mão de obra inovadora, a qualificação do trabalhador (renda e escolaridade), ao tamanho da empresa (número de empregados) e as importações. Nesse sentido, microeconomicamente as empresas mais produtivas são maiores, pagam maiores salários e empregam mão de obra inovadora e com maior escolaridade, além de apresentarem maior volume de importação. Essa característica é apresentada anteriormente em Negri \& Salerno (2005) para a indústria brasileira. A novidade deste estudo reside na verificação de que essas competências para inovar não são relevantes na esfera da indústria. Na esfera mesoeconômica, o perfil do trabalhador não é mais tão importante, destacando-se as exportações, o desenvolvimento de pedidos de patentes e a participação da empresa no mercado (share).

A diferença entre os fatores de influência na PTF das empresas industriais brasileiras nas esferas micro e meso indica uma complementaridade na Política Industrial. Pelo lado microeconômico, a estratégia da empresa é relevante e seu tamanho é o fator preponderante para seu sucesso. Na esfera mesoeconômica, a relevância da cooperação é maior e fatores estruturais destacam-se, como o volume de exportações e a concentração de mercado. As exportações articulam a cadeia de fornecedores da empresa, e o poder de mercado desta torna-se decisivo para comandar as demais empresas na tarefa de cooperação. Em outras palavras, com o controle setorial de cooperação, as empresas mais produtivas não são as importadoras, mas sim as exportadoras, também não são as maiores, mas as com maior poder de mercado (tamanho relativo, verificado no share). Percebe-se uma mudança dos fatores que explicam a produtividade das empresas industriais com a introdução da variável setorial sobre as competências microeconômicas para inovar.

Essa mudança sugere que a agregação de empresas é fundamental para o sucesso de certas políticas econômicas, como a exportação. Nesse sentido, se existem fatores sistêmicos relacionados à inovação e à dinâmica estrutural das empresas industriais, tais fatores devem ser levados em consideração na formulação de políticas públicas. Se a teoria Schumpeteriana conclui que as instituições importam para o processo de inovação da economia, os resultados aqui verificados mostram que muitas dessas instituições estão presentes e agem na esfera setorial, e o conceito de Sistema Setorial de Inovação de Malerna e Breschi se mostra importante na formulação de políticas públicas e estratégias empresariais de inovação e produção na indústria brasileira.

Esse resultado indica que a leitura da NEI sobre custos de transação, verticalização e formas de governança de mercado são importantes para o entendimento de como a cooperação se relaciona no processo de inovação e geração de ganhos de produtividade na indústria brasileira. A atual visão de Política Industrial no Brasil privilegia o processo de inovação sob o prisma microeconômico. As empresas de menor porte e os setores com menos poder de mercado (menos concentrados) são automaticamente marginalizados nessa proposta de política pública.

Os setores industriais também podem ser analisados em função das diferenças tecnológicas (Edquist 1997). Essa análise foge ao objetivo deste artigo, todavia, Steingraber (2009) e Steingraber \& Gonçalves (2011) não identificam diferenças no perfil tecnológico em relação aos ganhos de produtividade nos setores industriais brasileiros. Os resultados mostram a existência de diferen- 
ças entre os setores, mas sem a classificação conforme o perfil tecnológico (setores com baixa e alta intensidade tecnológica). Esse resultado, em conjunto com as estimativas apresentadas neste estudo, permite concluir pela falta de opção de setores vencedores na PI brasileira. Entretanto, a definição de políticas públicas deve abranger todos os setores, respeitando as especificidades setoriais e a relação micro e meso identificada.

O mesmo raciocínio desenvolvido anteriormente em relação à esfera tecnológica e setorial é aplicado na questão do território. O desconhecimento do peso do território sobre as especificidades da indústria é outro ponto de conflito na PI. A cooperação entre a empresa e sua cadeia pode estar concretizada em parâmetros de localização. Steingraber \& Gonçalves (2010) e Steingraber \& Gonçalves (2011) mostram o impacto da concentração geográfica sobre as competências para inovar e a PTF, repetindo os resultados aqui encontrados, ou seja, o fator setorial - concentração espacial nos dois estudos citados e cooperação para inovar neste - explica em grande medida a geração de ganhos de produtividade por meio das competências internas para inovar da empresa e que estão disponíveis espacialmente, ou seja, fica difícil falsear a ideia de que a cooperação é territorial e se dá pela proximidade entre as empresas. Nesse sentido, este artigo não buscou explicar os fatores que possibilitam o desenvolvimento da cooperação e estudos futuros podem explorar essas características, aplicando a questão territorial no modelo.

Novamente, a relação micro/meso mostra-se importante para explicar o desempenho da produtividade e da inovação nas empresas industriais brasileiras, todavia, essa relação ainda carece de maiores investigações teóricas e da definição de canais de incentivo nas políticas públicas de inovação e produção. Estudos futuros ainda podem explorar a esfera de definição de políticas públicas com a restrição macroeconômica, o que equivale à articulação do Sistema Nacional de Inovação no campo teórico do comportamento micro do inovador e do SSI.

\section{Conclusão}

Este estudo analisou o papel da cooperação no processo de inovação das empresas. Inicialmente, a cooperação no processo de inovação é definida em função do porte da empresa pela literatura Schumpeteriana. O tamanho da empresa é identificado como relevante no processo de inovação na esfera microeconômica. Os resultados estimados nesse exercício econométrico identificam diferenças entre as competências para inovar em função da cooperação no ambiente da empresa e da indústria.

Na esfera da empresa (microeconômica), as empresas mais produtivas são maiores, pagam maiores salários e empregam mão de obra inovadora e com maior escolaridade, além de apresentarem maior volume de importação. Com o controle setorial (esfera mesoeconômica) as empresas mais produtivas são as exportadoras, com maior número de pedidos de patentes e com maior tamanho relativo de mercado (poder de mercado).

Esse resultado confirma a visão de Sistema Setorial de Inovação (SSI), onde a cooperação no processo de inovação influencia o ganho de produtividade sob duas formas. No âmbito das competências da empresa para inovar, as variáveis diferem entre o ambiente interno (microeconômico) e o externo (setorial). 
Essa diferença mostra a importância do avanço teórico e da articulação de Políticas Industriais que pensem tais diferenças.

Estudos futuros podem explorar a relação entre a estrutura de governança da empresa na cadeia produtiva e o processo de inovação, aproximando as teorias Schumpeteriana e a Nova Economia Institucional (NEI) em função da estratégia de cooperação para inovar.

\section{Referências Bibliográficas}

Abramovitz, M. (1956), 'Resource and output trends in the united states since 1870', American Economic Review 46, 5-23.

Adams, W. J. (1970), 'Firm size and research activity: France and the united states', The Quarterly Journal of Economics 84(3), 386-409.

Aghion, P. \& Tirole, J. (1990), 'The management of innovation', The Quarterly Journal of Economics 109(4), 1185-1209.

Alves, J., Marques, M. J., Saur, I. \& Marques, P. (2007), 'Creativity and innovation through: multidisciplinary and multisectoral cooperation', Creativity and Innovation Management 16(1), 27-34.

Antonelli, C. (2003), The economics of innovation, new technologies and structural change, London: Routledge.

Baumol, W. J. (1992), 'Horizontal collusion and innovation', The Economic Journal 102(410), 129-137.

Becker, W. \& Dietz, J. (2004), 'R\&d cooperation and innovation activities of firms - evidence for the german manufacturing industry', Research Policy 33, 209-223.

Bidault, F., Despres, C. \& Butler, C. (1998), 'The drives of cooperation between buyers and suppliers for product innovation', Research Policy 26, 719-732.

Breschi, S. \& Malerba, F. (1997), Sectoral innovation systems: technological regimes, schumpeterian dynamics, and spatial boundaries, in C. o. Edquist, ed., 'Systems of innovation: technologies, institutions and organizations', London: Pinter, pp. 130-156.

Bó, P. (2005), 'Cooperation under the shadow of the future: experimental evidence from infinity repeated games', American Economic Review 95(5), 15911604 .

Bönte, W. \& Keilbach, M. (2005), 'Concubinage or marriege? informal and formal cooperation for innovation', International Journal of Industrial Organization 23, 279-302.

Cassiman, B. \& Veugelers, R. (2002), 'R\&d cooperation and spillovers: some empirical evidence from belgium', The American Economic Review 92(4), 1169-1184. 
Cassiman, B. \& Veugelers, R. (2005), 'R\&d cooperation between firms and universities. some empirical evidence from belgium manufacturing', International Journal of Industrial Organization 23, 355-379.

Chandler, A. D. (1977), The Visible Hand: The Managerial Revolution in American Business, Harvard: Belknap and Harvard University Press, Cambridge.

Cooke, P. (1992), 'Regional innovation systems: competitive regulation in the new europe', Geoforum 23(3), 365-382.

Cooke, P., Uranga, M. G. \& Etxebarria, G. (1997), 'Regional innovation systems: institutional and organizational dimensions', Research Policy 26(45), 475-491.

Dosi, G., Pavitt, K. \& Soete, L. (1990), The economics of technical change and international trade, London: Harvester Wheatshead.

Edquist, C. (1997), Systems of innovation: technologies, institutions, and organization, London: Routledge.

Faems, D., Looy, B. V. \& Debackere, K. (2005), 'Intereorganizational collaboration and innovation: toward a portfolio approach', The Journal of Product Innovation Management 22, 238-250.

Faria, P., Lima, F. \& Santos, R. (2010), 'Cooperation in innovation activities: the importance of partners', Research Policy 39, 1082-1092.

Fritsch, M. \& Franke, G. (2004), 'Innovation, regional knowledge spillovers and r\&d cooperation', Research Policy 33, 245-255.

Fritsch, M. \& Lukas, R. (2001), 'Who cooperates on r\&d?', Research Policy 30, 297-31.

Hox, J. (2002), Multilevel analysis techniques and applications, New Jersey: Lawrence Erlbaum Associates.

IBGE (2004), Pesquisa industrial de inovação tecnológica: série relatórios metodológicos, volume 30, Instituto Brasileiro de Geografia e Estatística.

Jorde, T. M. \& Teece, D. J. (1990), 'Innovation and cooperation: implications for competition and antitrust', The Journal of Economic Perspectives 4(3), 7596.

Lhuillery, S. \& Pfister, E. (2009), 'R\&d cooperation and failures in innovation projects: empirical evidence from french cis data', Research Policy 38, 45-57.

Malerba, F. (1992), 'Learning by firms and incremental technical change', The Economic Journal 102(413), 845-859.

Malerba, F. (2002), 'Sectoral systems of innovation and production', Research Policy 31(2), 247-264.

Mowery, D. C. (1998), 'The changing structure of the us national innovation system: implications for international conflict and cooperation in $\mathrm{r} \& \mathrm{~d}$ policy', Research Policy 27, 639-654. 
Mowery, D. C., Oxley, J. E. \& Silverman, B. S. (1996), 'Strategic alliances and interfirm knowledge transfer', Strategic Management Journal 17(Special Issue - Knowledge and the firm (winter)), 77-91.

Negassi, S. (2004), 'R\&d co-operation and innovation a microeconometric study on french firms', Research Policy 33, 365-384.

Negri, J. A. \& Salerno, M. S. (2005), Inovações, padrões tecnológicos e desempenho das firmas industriais brasileiras, Technical report, IPEA.

Nelson, R. R. \& Sampat, B. N. (2001), 'Making sense of institutions as a factor shaping economic performance', Journal of Economic Behavior E Organization $44(1), 31-54$.

Nelson, R. R. \& Winter, S. G. (1982), An Evolutionary Theory of Economic Change, Harvard University Press, Cambridge, MA.

Nooteboom, B. (2008), Collaboration, trust, and the structure of relationships, in B. Nooteboom \& E. Stam, eds, 'Micro-foundations for innovation policy', Amsterdam: Amsterdam University, pp. 199-218.

Oxley, J. E. \& Silverman, B. S. (2008), Inter-firm alliances: a new institutional economics approach, in E. Brousseau \& J. M. Glachant, eds, 'New institutional economics: a guidebook', Cambridge: Cambridge University, pp. 209234.

Penrose, E. T. (1959), The Theory of the Growth of the Firm, Wiley, New York.

Porter, M. (1998), 'Clusters and the new economics of competition', Harvard Business Review pp. 77-90.

Porter, M. (2000), 'Location, competition, and economic development: local clusters in a global economy', Economic Development Quarterly 14(15), 15-34.

Pyka, A. (2002), 'Innovation networks in economics: from the incentivebased to the knowledge-based approach', European Journal of Innovation Management 5(3), 152-163.

Steingraber, R. (2009), Inovação e produtividade: o papel dos sistemas de inovação para a indústria brasileira., Tese de doutorado, Universidade Federal do Paraná (UPRF).

Steingraber, R. \& Gonçalves, F. O. (2010), Inovação, instituições e capital social na produtividade total dos fatores da indústria brasileira em 2005, in M. S. Salerno, J. A. Negri, L. M. Turchi \& J. M. Moraes, eds, 'Inovações: estudo de jovens pesquisadores brasileiros', Vol. 2, Editora Papagaio, pp. 119-147.

Steingraber, R. \& Gonçalves, F. O. (2011), 'Brasil: diferencias de productividad em las empresas según sector industrial', Revista CEPAL 104, 123-140.

Teece, D. J. (1990), 'Competition, cooperation, and innovation organization arrangements for regimes of rapid technological progress', Journal of Economic Behavior and Organization 18, 1-25.

Tether, B. S. (2002), 'Who co-operates for innovation, and why: an empirical analysis', Research Policy 31, 947-967. 